\title{
WEAR BEHAVIOUR AND SURFACE ROUGHNESS OF POLYMER INFILTRATED CERAMIC MATERIAL COMPARED TO PRESSABLE GLASS CERAMIC
}

\author{
Elhomiamy $\mathrm{E}^{1} B D S$, Aboushady $\mathrm{Y}^{2} P h D$, El Malakh $\mathrm{B}^{3} P h D$.
}

\begin{abstract}
:
Introduction: Multiple restorative materials with various chemical, mechanical and physical characteristics are used as permanent dental restorations. The appropriate selection of a restorative material is crucial for preserving the occlusal harmony and normal masticatory function. Several aspects during selection of restorative materials should be considered, among which are the wear behaviour and abrasive nature of the restorative materials and natural enamel.

Objectives: The study determines the two-body wear and surface roughness measurement, of polymer infiltrated ceramic (Vita Enamic) and pressable lithium disilicate based ceramic (IPS e.max press).

Materials and methods: Two-body wear was investigated in custom made tooth wear brushing machine (60,000 cycles, $20 \mathrm{~N}$ and 60 cycle/min). The test specimens were divided into two groups, each group consisted of 8 ceramic specimens and 8 enamel cusp antagonists. Quantitative analysis of wear was carried out with subtractive weight loss of all specimens before and after wear test. Surface roughness measurements were evaluated before and after the wear test using a white light interference microscope. The data was collected and statistically analyzed using Mann-Whitney (U) test.

Results: Statically significant differences were found for two-body wear, with Vita Enamic samples show lower wear loss than IPS e.max press samples and cause less enamel wear loss. The Vita Enamic showed lower surface roughness and caused less surface roughness to enamel cusp antagonist than IPS e.max press samples.

Conclusions: Vita Enamic revealed lower wear loss contributed by terms of weight loss and surface roughness change than IPS e.max press. IPS e.max press contributed to more surface roughness and wear loss of opposing enamel than Vita Enamic.

Keywords: CAD/CAM - Two-body wear - Tooth brushing wear - Surface Roughness

1 Bachelor in dentistry, BDS, Faculty of Dentistry, University of Alexandria.

2 Professor of fixed prosthodontics, BDS, MSc, PhD, Conservative Dentistry Department, Faculty of Dentistry, University of Alexandria.

3 Professor of dental materials, BDS, MSc, PhD, Dental Biomaterial Department, Faculty of Dentistry, University of Alexandria.
\end{abstract}

\section{INTRODUCTION}

With the increase demand of esthetic materials, all ceramic restoration appeared and replaced old ceramo-metal restorations. The all ceramic restorations appear to mimic the natural dentition appearance as they lack metal core, they presented with good properties as biocompatibility, color stability and durability (1).

Wide ranges of all ceramic materials with various chemical, mechanical and physical characteristics were developed. Dental restorative materials should have good mechanical properties and wear resistance to withstand masticatory process and with low abrasive nature to opposing dentition (1). Several aspects during selection of restorative materials should be considered, among which are the wear behaviour and abrasive nature to natural enamel (2). Ideally, restoration materials should have wear resistance similar to that of enamel. The normal vertical loss of enamel from physiological wear was estimated to be approximately 20-38 $\mu \mathrm{m}$ per annum (3).

Wear is a complex cumulative process of multi factorial etiology, that characterized by progressive loss of material from its surface. Wear alters the anatomy of occlusal surface and affect the occlusal harmony and masticatory function $(4,5)$.

Pressable glass ceramic systems have gained their popularity due to their ease of fabrication, good mechanical properties, and relative kindness to natural dentition. The dimensional stability of pressed porcelain has made these ceramic materials excellent restorations. With the development of CAD/CAM technology new ceramic and composite materials were introduced that can be incorporated in all ceramic restoration fabrications (6).

Ceramic materials introduced tend to be more rigid and brittle and with potential hazard of excessive wear to opposing dentition. On the other hand the composite materials exhibit low mechanical properties and poor wear resistance but with low abrasive nature. Composite crowns showed preservation of occlusal anatomic form of $26.5 \%$ only versus $96 \%$ for ceramic crowns (7). A recent analysis mentions excess wear and loosening as the major clinical weaknesses of composite crowns (8), notwithstanding recent structural improvements, of resin-based materials may also be an issue if used for large restoration and multiple restorations in a quadrant (9).

Subsequently the developments of esthetic dental restorative materials have switched to more polymer based resin materials. New generation of restorative material was developed in the benefit of gaining both strength and color stability of dental ceramic and low abrasive nature of composite. These materials are known as hybrid dental ceramics, polymer infiltrated ceramic material is one of these hybrid materials (10).

One of the most recently introduced fully sintered $\mathrm{CAD} / \mathrm{CAM}$ block, the Vita Enamic material, is a polymer infiltrated ceramic form of feldspathic ceramic $86 \mathrm{wt} \%$ and polymer $14 \mathrm{wt} \%$. Vita Enamic polymer infiltrated ceramic material is manufactured by first infiltrating a porous 
feldspathic ceramic base structure with a monomer mixture of new cross linked polymethacrylate polymer material and then cured under high pressure and temperature. Vita Enamic is single visit monolithic restoration and surface shading and glazing is performed using special Polymerizable (light curing) stain and glaze kit. It is used as a single tooth restoration in the anterior or posterior zone (11).

The study was conducted to evaluate two-body wear and surface roughness measurement between the contact area on sliced block of polymer infiltrated CAD/CAM ceramic material and pressable lithium disilicate based glass ceramic materials on enamel cusp antagonist.

\section{MATERIALS AND METHODS}

Two types of ceramic materials were included in this study, esthetic CAD /CAM block Polymer infiltrated ceramic material (Vita Enamic) and pressable glass ceramic (IPS e.max press). Natural enamel (antagonist enamel cusp) was used as antagonist.

Specimen preparation: Sixteen freshly extracted caries free permanent upper first molars were collected from various general public hospitals intended for diabetic patient treatment. The extracted teeth were ultrasonically cleaned to remove any calculus and soft tissue remnant and then polished with non-fluoridated polishing paste and stored in saline solution. The antagonist enamel cusp specimens $(n=16)$ were prepared from the mesio-palatal cusp of upper maxillary first molar using high speed handpiece and long carbide fissure bur under water coolant (12). The antagonist enamel cusps were made into block using custom made copper mold and chemical cured acrylic resin (Self-cure acrylic resin, Vertex Dental Co., B.V., Netherland) showing approximately $3 \mathrm{~mm}$ of the enamel cusp (Fig. 1).

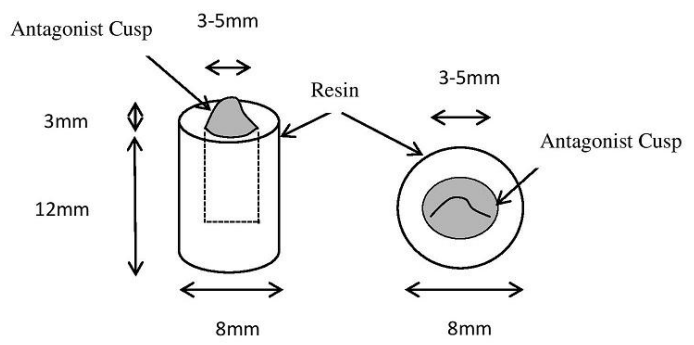

Fig. 1: Tooth antagonist cusp specimen illustration diagram.

The enamel antagonist cusp block was then stored in saline solution which was changed every 2 days to prevent dehydration of the enamel specimens.

Eight specimens of IPS e.max press (IPS e.max press, Ivoclar Vivadent, Schaan, Liechtenstein, Germany) ingot shade A2 was heat pressed in press furnace (Programmat EP 600) following the manufacturer recommendations. The IPS e.max press was made into slice of $(14 \times 12 \times 2 \mathrm{~mm}$ thickness) using Special copper mold. The specimen's surfaces were cleaned with blast of $\mathrm{Al}_{2} \mathrm{O}_{3}$ at 1 bar pressure followed by steam of air jet. Finishing was accomplished with glass ceramic finishing and polishing kit (Dialite LD finishing \& polishing kit, Brasseler, USA). The surface intended for wear test was finished to obtain smooth surfaces according to manufacture instruction and then glazed according to manufacturer instructions.

Eight test specimens of Vita Enamic (Vita Enamic, Vita Zhanfabrick, Bad Säckingen, Germany) were prepared from size 14 block $(18 \mathrm{~mm} \times 14 \mathrm{~mm} \times 12 \mathrm{~mm})$ using saw microtome (Micracut 150, precision cutter, Metkon instrument Inc., Bursa, Turkey). Precision cutting instrument diamond coated cutting disc (Diamond Coated Wavering Blade No 11-4276, Buehler) was used to cut off the block into a slice with size of $(14 \mathrm{~mm} \times 12 \mathrm{~mm} \times 2 \mathrm{~mm}$ thickness). The location of cuts was controlled using travelling stage and a horizontally displaced digital micrometer (13). The surface intended for wear test was finished with Vita Enamic polishing and finishing kit technical, then it was etched with $5 \%$ hydrofluoric acid gel for 60 seconds. The surface was carefully cleaned under running water to remove all acid remnants and air dried. Vita Enamic glaze was applied with fine brush evenly all over the surface and light cured for $60 \mathrm{sec}$ with Elipar LED curing unit (Elipar TM S10 led curing unite, 3M ESPE, St. Paul, MN, USA).

Wear testing procedures: Two-body wear for ceramic samples and their antagonist enamel cusp was conducted using special custom made tooth brushing wear machine (Dental Biomaterial department, Alexandria University). The custom made tooth brushing machine formed of two articulating parts; movable upper parts and fixed lower part. The antagonist enamel cusp blocks were fixed in the upper movable articulating bars while the ceramic samples were fixed in the lower fixed part using special plastic holder. Contact point geometry was established between the movable antagonist cusp specimens and fixed flat ceramic specimens as shown in (Fig. 2). Artificial saliva was used as a lubricating medium (14).

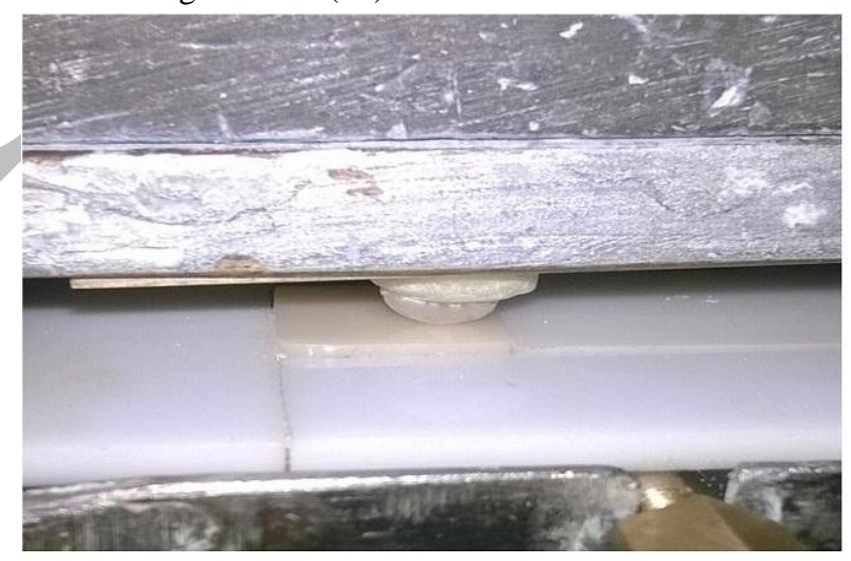

Fig. 2: Antagonist enamel cusp occluding flat ceramic specimen.

Wear test parameters: Two-body wear was conducted to total of sixteen ceramic specimens ( $n=8$ per material) antagonized by sixteen antagonist enamel cusp specimens. The wear test cycle strokes were to be a total of $(60,000$ cycles) with frequency of 60 cycle/ min and reciprocating displacement distance of 4-5 mm. A static load of $2 \mathrm{~kg}(20$ N) was used. 
Table 1: Mean \&standard deviation (SD) values and results for comparison in the weight loss between the two ceramic groups and natural teeth antagonist.

\begin{tabular}{|c|c|c|c|c|c|c|}
\hline \multirow{2}{*}{$\begin{array}{l}\text { Weight } \\
\text { change }\end{array}$} & \multicolumn{3}{|c|}{ Ceramic material } & \multicolumn{3}{|c|}{ Teeth antagonist } \\
\hline & $\begin{array}{c}\text { Vita } \\
\text { Enamic }\end{array}$ & $\begin{array}{l}\text { IPS e.max } \\
\text { press }\end{array}$ & $\mathrm{U}(\mathrm{P})$ & $\begin{array}{c}\text { Teeth } \\
\text { antagonize } \\
\text { vita Enamic }\end{array}$ & $\begin{array}{c}\text { Teeth } \\
\text { antagonize } \\
\text { IPS e.max } \\
\text { press }\end{array}$ & $\mathrm{U}(\mathrm{P})$ \\
\hline $\begin{array}{l}\text { Mean } \\
\text { weight } \\
\text { loss } \pm \\
\text { SD }\end{array}$ & $\begin{array}{c}1.5 \mathrm{mg} \\
\pm 0.7\end{array}$ & $\begin{array}{l}6.2 \mathrm{mg} \\
\pm 1.60\end{array}$ & $\begin{array}{c}3.3 \\
(0.001)^{*}\end{array}$ & $1.7 \mathrm{mg} \pm 0.6$ & $\begin{array}{r}10.2 \mathrm{mg} \\
\pm 2.8\end{array}$ & $3.3(0.001)^{*}$ \\
\hline $\begin{array}{l}\text { Mean } \\
\text { weight } \\
\text { loss \% } \\
\pm \text { SD }\end{array}$ & $\begin{array}{l}0.24 \% \\
\pm 0.11\end{array}$ & $\begin{array}{l}0.71 \% \\
\pm 0.25\end{array}$ & $\begin{array}{c}3.2 \\
(0.001) *\end{array}$ & $0.16 \% \pm 0.05$ & $\begin{array}{l}0.88 \% \\
\pm 0.27\end{array}$ & $3.0(0.001)^{*}$ \\
\hline
\end{tabular}

U: Mann-Whitney test

$* \mathrm{P}<0.05$ (significant level)

Quantitative and qualitative analysis of two-body wear:

Quantitative analysis of two-body surface wear of ceramic specimens and their antagonist enamel cusp specimens was subjected to weight loss assessment and surface roughness $(\mathrm{Ra})$ change (15).

The samples were weighted before and after the wear test using sensitive electronic balance (Analytical Balance, Scaltec SPB 31, Scaltec instruments GmbH, Robert-BoschBreite, 1037079 Göttingen, Germany). Wear in a test sample was defined as the weight loss of specimens to have occurred by subtracting initial weight from the final weight measurements. Surface roughness (Ra) change was calculated using white light interference microscope (Interference Microscope, ZYGO Maxim-GP 200, ZYGO Lot $\mathrm{GmbH}$, Boston, Middlefield, CT, USA). The occluding surface for each specimen was scanned and the surface roughness was measured before and after the wear test.

Qualitative analysis of wear patterns, the selected specimens were examined under backscattering scanning electron microscope (SEM) (Jeol JSM 5300, Stoneridge, 122 Pleasanton, CA, USA). Each sample was scanned under two different level magnification, overall view of the wear scar with (X500) magnification and magnified view with (X2000) magnification to give detail analysis of the wear scar.

\section{Statistical analysis}

The data sets were analyzed with statistical software (IBM SPSS Version 20, IBM Germany). Descriptive statistics with mean, standard deviation and $95 \%$ confidence intervals for all tests and groups were computed. For the two-body wear results, statistical differences between the tested materials as well as the corresponding antagonists regarding (mean weight loss weight loss percent, mean surface roughness change and surface roughness percent change) were assessed with Mann-Whitney (U) test.

Mean value weight change: (weight before wear test) (weight after wear test).
$($ Percent weight loss $)=($ WI-WF $) /$ WI X 100

Where; WI = initial weight before wear test in $(\mathrm{mg})$

$\mathrm{WF}=$ final weight after wear test in $(\mathrm{mg})$

Mean value change in surface roughness ( $\mathrm{Ra})$ : ( $\mathrm{Ra}$ after wear test) - (Ra value before wear test).

Surface roughness percent change $=(\mathrm{RaF}-\mathrm{RaI}) / \mathrm{RaI} X 100$

Where $\mathrm{RaI}=$ initial surface roughness value before wear test in $(\mu g)$

$\mathrm{RaF}=$ final surface roughness value after wear test in $(\mu \mathrm{g})$

\section{RESULTS \\ Quantitative analysis}

Regarding weight loss: There was statistically significant difference between the two ceramic groups. The higher weight loss occurred in the IPS e.max press samples with mean value of $(6.2 \pm 1.6 \mathrm{mg})$ and total percent change of $(0.71 \% \pm 0.25)$, while the Vita Enamic samples revealed lower mean weight loss with value of $(1.5 \pm 0.07 \mathrm{mg})$ and total percent change of $(0.24 \% \pm 0.11)$ as shown in (Table 1$)$.

There was statistically significant difference in the enamel cusp antagonist samples. The higher weight loss occurred in the enamel cusp antagonist opposed by IPS e.max press group with a mean value of $(10.2 \pm 2.8 \mathrm{mg})$ and total percent of $(0.88 \% \pm 0.27)$. While it was lower in the enamel cusp antagonist samples opposed by the Vita Enamic group with mean weight loss value of $(1.7 \pm 0.6 \mathrm{mg})$ and weight percent loss of $(0.16 \% \pm 0.05)$ as shown in (Table 1) \& (fig. 3)

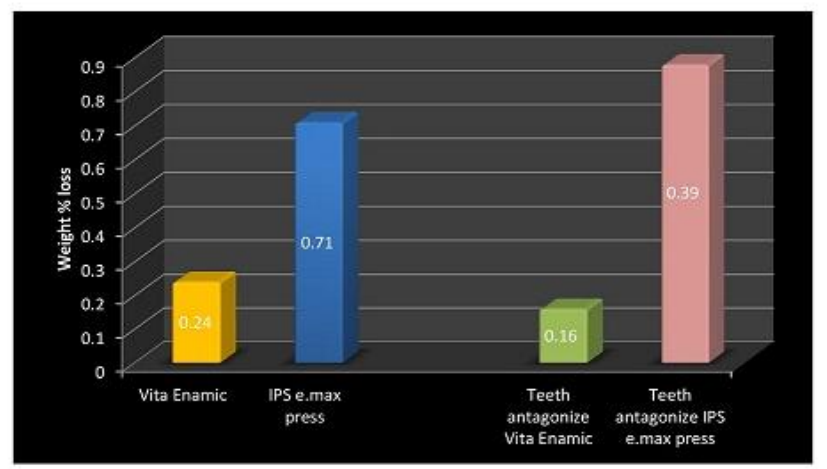

Fig. 3: Bar chart represents the mean weight loss percent in the two ceramic systems and natural teeth antagonist.

Regarding surface roughness: Surface texture analysis of test specimens revealed that there was statistically significant difference between the two ceramic groups, the higher surface roughness change occurred in the IPS e.max press samples with mean value of $(0.15 \pm 0.10 \mu \mathrm{m})$ and total percent change of $(82.6 \% \pm 37.1)$. While Vita Enamic samples revealed lower mean surface roughness change value of $(0.06 \pm 0.03 \mu \mathrm{m})$ and total percent change of $(48.7 \%$ \pm 23.9 ) as shown in (Table 2).

There was statistically significant difference in the enamel cusp antagonist samples with the higher surface roughness change occurred in the enamel cusp antagonist opposed by IPS e.max press group with mean change value of $(0.18 \pm 0.11 \mu \mathrm{g})$ and total percent change value of $(189 \%$ $\pm 147)$. While it was lower in the enamel cusp antagonist 
samples opposed by Vita Enamic group with mean surface roughness change value of $(0.06 \pm 0.08 \mu \mathrm{g})$ and surface roughness percent change of $(78 \% \pm 108)$ as shown in (Table 2) \& (fig. 4).

Table 2: Mean \&standard deviation (SD) values and results for Mann Whitney test, for comparison in surface roughness change between the two ceramic groups and natural teeth antagonist.

\begin{tabular}{|c|c|c|c|c|c|c|}
\hline \multirow{2}{*}{$\begin{array}{l}\text { Surface } \\
\text { roughness } \\
\text { change }\end{array}$} & \multicolumn{3}{|c|}{ Ceramic material } & \multicolumn{3}{|c|}{ Teeth antagonist } \\
\hline & $\begin{array}{c}\text { Vita } \\
\text { Enamic }\end{array}$ & $\begin{array}{l}\text { IPS } \\
\text { e.max } \\
\text { press }\end{array}$ & $\mathbf{U}(\mathbf{P})$ & $\begin{array}{c}\text { Teeth } \\
\text { antagonize } \\
\text { vita Enamic }\end{array}$ & $\begin{array}{c}\text { Teeth } \\
\text { antagonize } \\
\text { IPS e.max } \\
\text { press }\end{array}$ & $\mathbf{U}(\mathbf{P})$ \\
\hline $\begin{array}{c}\text { Mean } \\
\text { surface } \\
\text { roughness } \\
\text { change } \pm \\
\text { SD }\end{array}$ & $\begin{array}{l}0.06 \pm \\
0.03 \mu \mathrm{g}\end{array}$ & $\begin{array}{c}0.15 \mu \mathrm{g} \\
\pm 0.10\end{array}$ & $\begin{array}{c}2.5 \\
(0.011)^{*}\end{array}$ & $0.06 \mu \mathrm{g} \pm 0.08$ & $\begin{array}{c}0.18 \mu \mathrm{g} \\
\pm 0.11\end{array}$ & $\begin{array}{c}2.0 \\
(0.035) *\end{array}$ \\
\hline $\begin{array}{c}\text { Mean } \\
\text { surface } \\
\text { roughness } \\
\% \text { change } \\
\pm \text { SD }\end{array}$ & $\begin{array}{c}48.7 \% \pm \\
23.9\end{array}$ & $\begin{array}{c}82.6 \% \pm \\
37.1\end{array}$ & $\begin{array}{c}2.0 \\
(0.042)^{*}\end{array}$ & $78 \% \pm 108$ & \pm 147 & $\begin{array}{c}2.0 \\
(0.040)^{*}\end{array}$ \\
\hline
\end{tabular}

U: Mann-Whitney test $* \mathrm{P}<0.05$ (significant)

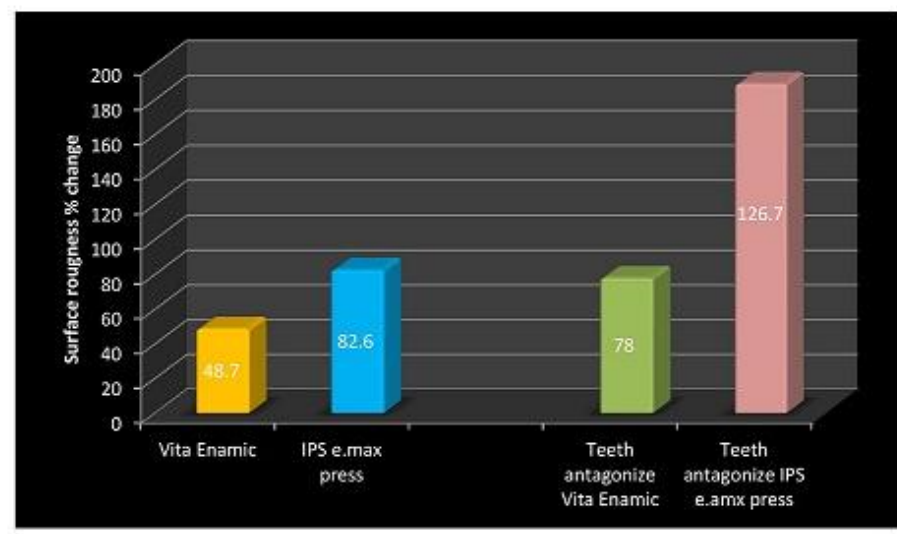

Fig. 4: Bar chart represents the mean surface roughness percent change in the two ceramic systems and natural teeth antagonist.

\section{Qualitative analysis}

The results of the qualitative SEM analysis are presented in (Fig. 5, 6) showing image pairs of contact areas on ceramic specimen and corresponding enamel cusp. SEM analysis of Vita Enamic samples revealed narrow, shallow and smooth wear scar as shown in (Fig. 5), with high magnification the wear surface revealed multiple small surface cracks and chipping off the ceramic surface. Antagonist enamel revealed smooth and small area of wear scar with small surface cracks accompanying with the formation of pit-like structure defects.

SEM observation of IPS e.max press samples revealed wider and deeper wear scar. The wear scar revealed multiple surface irregularities corresponding to area of abrasion (Fig. 6).
On high magnification the surface presented with needle shape crystals and fragment of antagonist teeth. Antagonist enamel show large wear scar area with multiple surface cracks, rough furrows and enamel flakes. High magnification imaging of enamel surface revealed the formation of multiple small cracks and peeling-off the enamel surface.

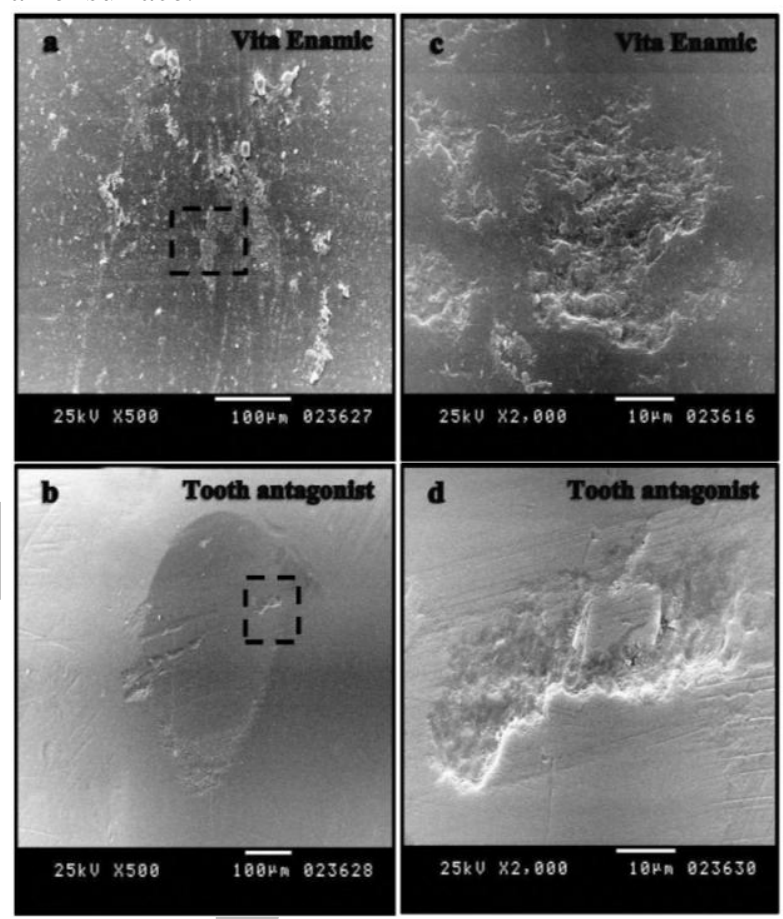

Fig. 5: SEM images of Vita Enamic and tooth antagonist, a \& b represents overall view of wear pattern, c \& d represents magnified yiew.
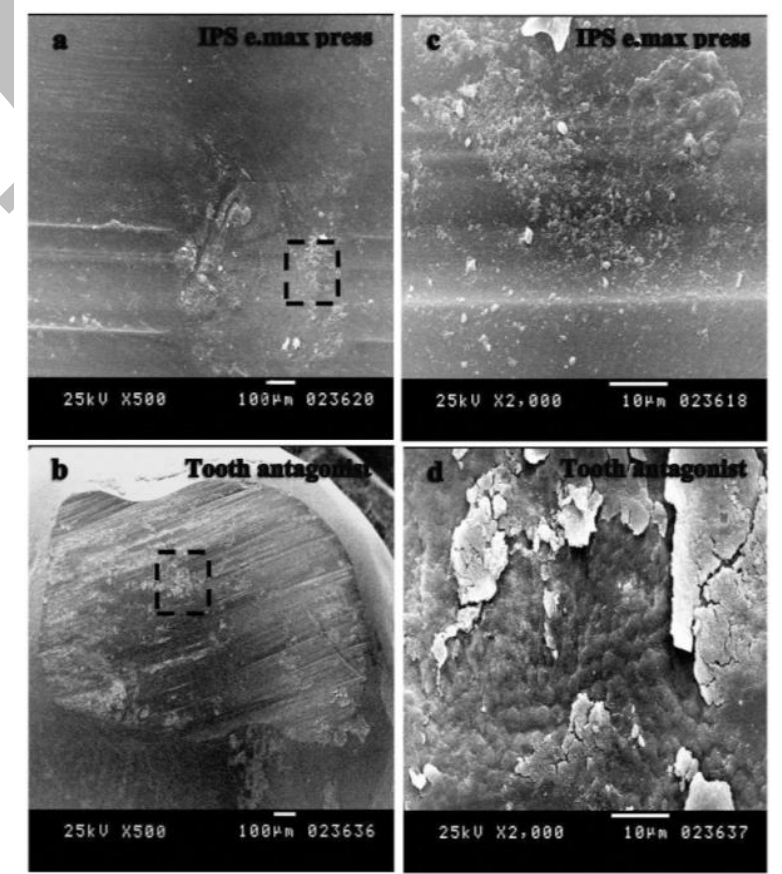

Fig. 6: SEM images of IPS e.max press and tooth antagonist, a \& b represents overall view of wear pattern, c \& d represents magnified view. 


\section{DISCUSSION}

Tooth wear is a complex process that involves many variables, such as age, para-fuctional habits, neuromuscular force, thickness and hardness of enamel, properties of saliva, masticatory pattern and nature of restorative materials (16). The study of dental wear become common through the biomaterials literatures due to wide variety of dental restorative materials introduced (17).

Laboratory wear testing procedure (in-vitro) may have limitations in reflecting the intraoral condition. It can't perfectly simulate the intraoral masticatory movement; they can only simulate simple movement such as grinding and clenching (18). The obtained results are helpful in comparing materials under controlled condition, as well as useful in prediction of their clinical performance (19). Wide variety of in-vitro wear test parameters revealed in the publications concerning the applied force, numbers of cycles, design and frequency suggested that there is no agreement between studies. Difficulty in standardization and the impact of methodological or operator own modifications could make direct comparisons between studies almost impossible (20).

In this study we followed the regime for wear testing at a rate of $60 \mathrm{cycle} / \mathrm{min}$ for total of $(60,000$ cycles) under a load of $(20 \mathrm{~N})$ in reciprocating distance of (4-6 $\mathrm{mm})$ which represents (120 days) as described by lmai et al (21). The load of $20 \mathrm{~N}$ used in this study applied on a small sample, that simulates a tooth cuspid determines high tension values over the restoration according to Coppedê et al. 2013 (22) and Faria et al (23).

The tooth sample of mesio-palatal cusp of upper first maxillary molar was used in this study as recommended by (Kerjici et al) (24). Many authors recommend flat planes of enamel prepared from labial surface or mesial or distal surface of the tooth (25). The cuspal enamel was to be found much stronger than the enamel found on the side of a tooth and is stronger under compression. Consequently using cusp specimens was more clinically relevant as agreed by (AlHiyasat et al) (26).

In this study under the two-body wear condition, it was revealed that there was statistically significant difference $(\mathrm{P}$ $<0.05)$ between the two ceramic groups. The IPS e.max Press showed higher wear loss and surface roughness change in comparison to Vita Enamic. There was statistically significant difference between the enamel cusp antagonists groups with the higher wear loss and surface roughness change in the enamel antagonist cusp opposed by IPS e.max press; in contrast Vita Enamic resulted in lower wear loss of enamel antagonist cusp. The test results were in agreement with Mormann et al, Hientze et al, Kim et al and Peng et al. (13, 27-29).

Vita Enamic, wear behaviour and surface roughness results obtained in this study are in agreement with Mormann et al (13). They studied the two-body wear and tooth and roughness measurement of different kind of dental ceramic and composite materials including Vita Enamic. Their results revealed that Vita Enamic showed lower wear loss than most tested materials except for zirconia based ceramic, also they reported that Vita Enamic resulted in lower wear loss to the antagonist enamel cusp.

Mormann et al (13), also reported that the wear behavior of vita Enamic was similar to natural enamel, under SEM imaging of the contact area representing as a sharp line with minimal cracks and pitting defects giving criteria of fatigue wear which was confirmed by the present study. This may be attributed due to that Vita Enamic is interpenetrating phase composite with combination of ceramic (feldspathic) and acrylated base resin polymer. Vita Enamic is damage tolerant, the reaction of Vita Enamic to repetitive impact of the antagonist may be influenced by its modulus of elasticity and flexural strength which showed some degree of elastic deformation under load as reported by Coldea et al (30).

The IPS e.max press, wear behaviour and surface roughness results obtained in this study were in accordance with Hientze et al (27). They reported that IPS e.max press showed lower wear loss and in comparison to Empress and Design, however they also reported that IPS e.max press showed higher friction coefficient. Kim et al (28) found that the IPS e.max press showed lower wear loss in comparison to other glass ceramic except for zirconia based ceramic. Hientze, Kim and Peng et al., reported that SEM images of IPS e.max press showed surface roughness with lateral surface cracks and delamination of ceramic surface representing abrasive wear as observed in this study.

The test results were in disagreement with Peris et al (31) and Albashaireh et al (32), they reported that the wear loss of IPS e.max press was lower to zirconia based ceramic. They also added that IPS e.max press caused lower wear loss to antagonist enamel cusp. The wear behaviour observed by Albashaireh et al (32) of the IPS e.max press showed fragment loss with superficial and deep surface cracks giving sign of fatigue wear which could be contributed due to they used zirconia ball as antagonist.

The publication is controversial about glazing and polishing on the wear behaviour of ceramic materials. In this study all ceramic samples surfaces were finished with glaze layer according to manufacturer instruction. Ling Wang et al (14) and Albashaireh et al (32), reported that the wear behavior of polished IPS e.max press has been lower to that of glazed one. The glaze material will often be removed early during wear cycle leaving underlying rough surface. This could be attributed to that the micro structure of IPS e.max press glass ceramic is not completely free of porosities and/or pores. Surface porosities may cause primarily by volume changes associated with thermal differences during processing and from human errors during the preparation procedure and fabrication stages (33).

The inner properties of ceramic affect the wear rate once the effect of surface roughness disappeared with wear progression (34), Vita Enamic presented with low friction coefficient due to the presence of polymer interpenetrating phase which birding the ceramic phase surface causing surface crack deflections as reported by Alvaro Della et al (35).

Ling Wang et al (14) reported that the frictional 
coefficient of polished IPS e.max press glass ceramic was higher than polished zirconia based ceramic when antagonized natural enamel. In contrast Peng et al (29) reported that the highest frictional coefficient was reported in the highly polished IPS e.max press samples, which could be attributed to the use of $\mathrm{Al}_{2} \mathrm{O}_{3}$ ceramic ball as antagonist.

The hardness of IPS e.max press was reported to be higher than Vita Enamic (35 - 37). However in this study the wear loss of IPS e.max press was higher than Vita Enamic. This could be contributed to that Surface hardness IPS e.max press glass ceramic has been reported to be affected by repeating loading especially in wet condition as reported by Wang et al, Belli et al and Won Suck et al $(34,38,39)$. Corrosion mechanism of glass matrix occurred by the diffusion of positive water ions into glass matrix, which caused ploughing of surface molecule from the ceramic surface and reducing surface hardness.

On the other hand Vita Enamic is polymer based ceramic fear of influence of water adsorption through the polymer layer and interfacial salinized polymer feldspar interface which could alter the mechanical properties. Ruse and Sadoun 2014 (40), reported that the mechanical properties of Vita Enamic after aging process was merely affected.

\section{CONCLUSIONS}

Within the limitations of this in-vitro study, the following conclusions can be drawn:

1. Vita Enamic showed a lower wear loss and causes less wear damage on opposing enamel than IPS e.max Press.

2. The surface roughness change of Vita Enamic was much lower than IPS e.max Press and all ceramic material show lower surface roughness change than opposing enamel.

\section{STATEMENT OF CONFLICT:}

The authors declare that they have no conflicts of interest.

\section{REFERENCES}

1. Mehta S.B., Banerji S., Millar B.J. and Suarez-Feito J.M. Current concepts on the management of tooth wear: part 1. Assessment, treatment planning and strategies for the prevention and the passive management of tooth wear. British dent. J 2012; 212: 17-27.

2. Kim S.K., Kim K.N., Chang L.T. and Heo S. J. A study the effects of chewing pattern on occlusal wear. $J$ of oral rehab. 2001; 28: 1048-1055.

3. Lambrechts, P., Braeme, M., Vuylsteke-Wauters, M., Vanherle, G. Quantitative in vivo wear of human enamel. Journal of Dental Research 1989; 68: 17521754.

4. Lewis R. and Dwyer-Joyce R. Wear of human teeth a tribiological perspectives. $\mathrm{J}$ of Tribiological Engine. 2005; 219: 2-19.

5. Hahnel S., Schultz S., Trempler C., et. al. Two-body wear of dental restorative materials. J Mech Behav Biomed Mater. 2011; 4: 237-244.

6. Albakry M., Guazzato M., Swain M.V. Fracture
Toughness and Hardness Evaluation of Three Pressable All-Ceramic Dental Materials. J of Dentistry 2003; 31(3): 181-188.

7. Vanoorbeek, S., Vandamme, K., Lijnen, I., Naert, I.,. Computer-aided designed/computer-assisted manufactured composite resin versus ceramic single-tooth restorations: a 3-year clinical study. International Journal of Prosthodontics 2010: 23 (3), 223-230.

8. Kelly, J.R., 2011. Article analysis and evaluation: Computer-Aided Designed/Computer-Assisted Manufactured (CAD/CAM) all- ceramic crowns appear to perform better than all-composite resin crowns following the first 3 years of placement. Journal of Evidence-Based Dental Practice 11, 203-205.

9. Ferracane,J.L.,2011.Resin composite-state of the art. Dental Materials 27,29-38.

10. Kelly R. Computer-Aided Designed/Computer-Assisted Manufactured (CAD/CAM) All-Ceramic Crowns Appear to Perform Better than All Composite Resin Crowns Following the First 3 Years of Placement. J of Evidence Based Dental Practice 2011; 11(4): 203-205.

11. Drik Osterman. High-tech material for chair side CAD/CAM: Vita Enamic. J of digital dental news, Jan/Feb 2013.

12. Heintzea S.D., Cavalleri A., Forjanica M., Zellwegera G., Roussonb V. Wear of ceramic and antagonist-A systematic evaluation of influencing factors in vitro. $\mathrm{J}$ of dental materials 200 8; 2 4: 433-449.

13. Mormanna W. H., Stawarczyk B., Endera A., Senerc B., Attinc T., Mehla A. Wear characteristics of current aesthetic dental restorative CAD/CAM materials: Twobody wear, gloss retention, roughness and Martens hardness. J o f mechan. Behave. Of biomedical materials. 2013; 20: 113-125.

14. Lin Wang A., Yihong Liu A., Wenjie Si B., Hailan Feng A., Yongqing Tao A., Zhizuo Mac. Friction and wear behaviors of dental ceramics against natural tooth enamel. J of the European Ceramic Society 2012; 32: 2599-2606.

15. Adriana Claudia. New resistance of pressable low fusing ceramic opposed by dental alloys. $\mathrm{J}$ of mechanical Behaviour Of biomedical material. 2014; 32: 46-51.

16. Elmaria A., Goldestien E. an evaluation of wear when enamel is opposed by various ceramic materials and gold. J. of prosth. Dent. 2006; 96: 345-53.

17. Sulong M. and Aziz R. A. Wear of materials used in dentistry: A review of the literature. $\mathrm{J}$ of Prosth Dent.1990; 63: 342-349.

18. Suzuki S. Does the wear resistance of packable composite equal that of dental amalgam. J Esthetic Restor. Dent. 2004; 16: 355-365.

19. Yip K., Smales R. and Kaidonis J. Differential wear of teeth and restorative materials: clinical implications. Int J Prosthodont. 2004; 17: 350-356.

20. Al-Hiyasat A.S., Sanders S.W. investigation of human wear against four dental ceramic and gold. j. of dentistry. 1998;26: 487-499. 
21. Imai Y., Suzuki S. and Fukushima S. Enamel wear of modified porcelains. Am J Dent. 2000; 13: 315-323.

22. Coppede A.R., Faria, A.C.L., Mattos, M.G.C., Rodrigues, R.C.S., Shibli, J.A., Ribeiro, R.F., 2013. Mechanical comparison of experimental conical-head abutment screws with abutment screw with conventional flat-head abutment screws for external-hex and internal tri-channel implant connections: an in vitro evaluation of loosening torque. Int $\mathbf{J}$ Oral Maxillofac Implants. 2013; 28(6): 321-9.

23. Faria A. C., Oliveria A. A., Gomes E. A., Rodriges R. C., Ribeiro R. F. Wear resistance of pressable low fusing ceramic opposed by dental alloys. J of mech. Behav. Of biom. Materials. 2014; 32: 40-51.

24. Krejci I., Albert P., and Lutz F. The Influence of Antagonist Standardization on Wear. J of Dent Res 1999; 78(2): 713-719.

25. Anusavice K.J. Science of Dental Materials, 11th ed. Phillips, W.B. Saunders, St.

26. Al-Hiyasat A.S., Sanders S.W. investigation of human wear against four dental ceramic and gold. j. of dentistry. 1998;26: 487-499.

27. Heintze S.D. Corvallei A. wear of ceramic and antagonist a systemic evaluation influence factor in vitro. Dental material, 2008; 260: 1256-1261.

28. Kim M. J., Oh S. H., Kim J. H. et. al. Wear evaluation of human enamel opposing different Y-TZP dental ceramics and other porcelains. J of dentistry. 2012; 40: 979-88.

29. Peng Z., Abd Elrahman M. E. Zhang Y., Yin L. Wear behavior of pressable lithium disilicate glass ceramic. J of Biomedical Materials Research: Applied Biomaterials. 2015; 40; 1032-40.

30. Andrea Coldea, Michel swain and Norbert F. mechanical proprieties of polymer infiltrated ceramic network material. J of Dent. Mater. 2013; 29: 419-26.

31. Preis V., Hannel S., Kolbeck C. et al. Wear Performance of Dental Materials: A Comparison of Substructure Ceramics, Veneering Ceramics, and NonPrecious Alloys. J of advanced biomaterials. 2011; 12; B432-B439.

32. Albashaireh z. Two-body wear of different ceramic materials opposed to zirconia ceramic. J of prosth. Dent. 2010; 104 (2): 105-13

33. Won-suck O.H., Ralph DeLong A., and Kenneth J. Factors affecting enamel and ceramic wear: A literature review. J OF PROSTH. DENT. 2002; 48 (4): 451-59.

34. Metzelr K.T., Woddy R.D. in investigation of the wear of human enamel by dental porcelain. J. of prosth. Dent., 1999; 81: 356-64.

35. Alvaro Della Bona, Pedro H., Corrazzo. Y.U. Characterization of polymer infiltrated ceramic network material. J of Dent. Mater. 2014; 30 (5): 564-569.

36. Monmaturapoj N., Lawita P. and Thepsuwan W. Characterization and Properties of Lithium Disilicate Glass Ceramics in the SiO2-Li2O-K2O-A12O3 System for Dental Applications. Advances in Materials Science and Engineering. 2013; 1-11.
37. Conrad H. J., Seong W. J. and Pesun, I. J. Current ceramic materials and systems with clinical recommendations: A systematic review. J Prosth. Dent. 2007; 98: 389-404.

38. Wang R. R., Lu C. L., Wang G., Zhang D. S. Influence of cyclic loading on the fracture toughness and load bearing capacities of all ceramic crowns. Int. JA of oral science. 2013; 6: 99-104.

39. Belli R., Genzier E., Muschweck A., Petschelt A., Lohbaue U. Mechanical fatigue degradation of ceramics versus resin composites for dental restorations. Dental material j. 2014: 30 (4): 424-432.

40. Thornton I., Ruse N.D. Characterization of nanoceramic resin composite and lithium disilicate blocks for CAD/CAM. J Dent Res. 2014; 93: 898-902. 